\title{
Bulbus ülseri her zaman benign bir hastalık olmayabilir
}

\author{
Bulbus ulcer may not be a benign condition at all times
}

Züleyha AKKAN ÇETINKAYA ${ }^{1}$, Mesut SEZIKLI², M. Tahir ORUÇ ${ }^{3}$, Alp Mustafa GÜNAY ${ }^{4}$, Fatih GÜZELBULUT ${ }^{1}$, Hakan DEMIRCI $^{5}$

Kocaeli Derince Eğitim ve Araştırma Hastanesi, ${ }^{1}$ Gastroenteroloji, ${ }^{3}$ Genel Cerrahi, ${ }^{5}$ Patoloji, Kocaeli

Haydarpașa Numune Eğitim ve Araștırma Hastanesi, ${ }^{2}$ Gastroenteroloji, Istanbul

Özel Konak Hastanesi, ${ }^{4}$ Gastroenteroloji, Izmit

Ince barsak malign tümörleri tüm gastrointestinal traktüs malign tümörlerinin içinde az bir kısmı oluşturur. En sık adenokarsinoma görülür. Bulbus ülseri günlük pratikte endoskopistlerin sık gördügüü patolojilerdendir. Bu yazıda bulbus ülseri şeklinde presente olan duodenum 1. kısım adenokarsinomu olgusu sunulmaktadir.

Anahtar kelimeler: Ince barsak tümörü, adenokarsinom, duodenum, gastroskopi

\section{GİRISs}

Primer gastrointestinal traktüs tümörlerinin \%5'inden azı ince barsaklardan kaynaklanır. Adenokarsinoma, karsinoid tümör, lenfoma ve sarkoma ince barsaklarda en sık görülen 4 tümör cinsidir. Yapılan pek çok çalışmaya göre en sık adenokarsinom görülürken, bunu karsinoid tümörler takip eder. Adenokarsinomalar en sık duodenumda görülürken, karsinoid ve lenfoma daha çok jejunum ve ileumda görülür (1-3). Duodenumda ampulla vateri kaynaklı adenokarsinomalar daha sık görülürken, 1. kısımdan köken alan kanserler nadirdir. Bu yazıda bulbusdan kaynaklanan bir adenokarsinom vakasını sunmaktayı.

\section{OLGU SUNUMU}

Altmışaltı yaşında erkek hasta, 6 ayda 10 kg zayıflama ve karnın sağ tarafında ağrı şikayeti ile polikliniğe başvurdu. Hipertansiyon dışında başka bilinen hastalığı yoktu. 6 ay önce şikayeti başladığında dış merkezde yapılan gastroskopide pangastrit, bulbusta apeks ön duvarda frajil, kısmi darlık yapan ülser saptanmış. Kolonoskopi ve batın ultrasonografi normal olarak değerlendirilerek, hasta takibe alınmış.

Şikayetleri devam eden hasta hastanemiz gastroenteroloji polikliniğine başvurduğunda yapılan fizik muayene normaldi. Hemogram ve biyokimyasal tetkikler normal, gaitada gizli kan negatifti. Hastaya yapılan tetkiklerde sadece önceki gastroskopide patolojik bulgu saptandığı için yeniden değerlendirme amaçlı gastroskopi yapıldı. İncelemede bulbusta ikinci kıtaya geçişi zorlaştıran ancak engellemeyen polipoid ülsere
Malignant tumors of the small intestine account for the minority of tumors throughout the gastrointestinal tract. Adenocarcinoma is the most common of all malignant tumors. Duodenal ulcer located in the bulbus is one of the most frequent entities seen by endoscopists in daily clinical practice. In this report, we present a case with adenocarcinoma of the first part of the duodenum, which was presented as a bulbus ulcer.

Key words: Small intestinal tumor, adenocarcinoma, first part of duodenum, gastroscopy

lezyon saptandı ve malignite düşünülerek, biyopsiler alındı (Şekil 1, 2). Histopatolojik inceleme sonucu adenokarsinoma ile uyumlu bulunan hastaya olası metastaz açısından batın tomografisi çekildi; normal saptandı. Preoperatif yapılan pozitron emisyon tomografi ve bilgisayarlı tomografi incelemesinde bulbus dişında radyoaktif madde tutulumu izlenmedi. Bu bulgularla operasyon için genel cerrahi kliniğine nakil edilen hastaya Whipple operasyonu yapıldı ve hasta postoperatif komplikasyonsuz olarak taburcu edildi.

\section{TARTIŞMA}

Ince barsak tümörlerinin gelişiminde bazı risk faktörleri tanımlanmıştır. Rafine karbonhidratlardan, şekerden ve kırmızı etten zengin beslenme malignite riskini arttırırken, balık, meyve ve sebze tüketiminin koruyucu etkisi gösterilmiştir. Diyet yanında erkek cinsiyet, ileri yaş, Çölyak hastalığı, Crohn hastalığı ve polipozis sendromları da riski arttıran faktörlerdendir $(4,5)$.

Hastalığın bulgu ve belirtileri direkt olarak tümörün lokalizasyonu ile ilgilidir. Duodenum adenokarsinomalarında nadiren intestinal obstrüksiyon belirtileri görülürken, gizli veya aşikar kan kaybı ile beraber karın ağrısı ve biliyer obstrüksiyon da görülebilir. Daha distal yerleşimli jejunum ve ileum tümörlerinde ise semptomlar daha belirsiz olup, nonspesifik karın ağrısı, bulantı, kusma ve abdominal distansiyonla beraber gizli veya aşikar kanama da görülebilir. 


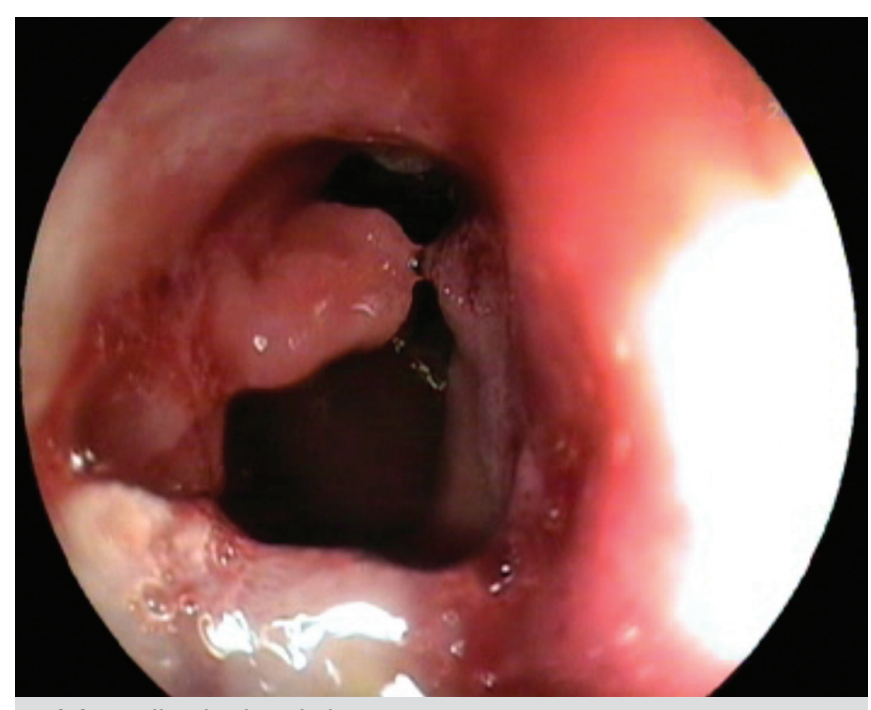

Şekil 1. Bulbusda ülsere kitle

Tanıda endoskopik incelemenin önemi büyüktür. Standart gastroskop ile ulaşlamayan ince barsak tümörlerinin tanısında video kapsül endoskopi, çift balon endoskopi, çeşitli bilgisayarlı tomografi modaliteleri ve endoskopik ultrasonografiden faydalanilır (6).

Ince barsak adenokarsinomaları için tek bilinen küratif tedavi yöntemi cerrahidir. Küratif cerrahi rezeksiyon hastaların \%4065'li arasında başarılı bulunmuştur. Duodenum adenokarsinomalarında cerrahi seçenek Whipple operasyonudur (7).

\section{KAYNAKLAR}

1. Wilson JM, Melvin DB, Gray GF, Thorbjarnarson B. Primary malignancies of the small bowel: a report of 96 cases and review of the literature. Ann Surg 1974; 180: 175-9.

2. Egberts JH, Scharrer ML, Hinz S, et al. Small bowel cancer: single-centre results over a period of 12 years. Hepatogastroenterology 2007; 54: 129-34.

3. Mittal VK, Bodzin JH. Primary malignant tumors of the small bowel. Am J Surg 1980; 140: 396-9.

4. Negri E, Bosetti C, La Vecchia C, et al. Risk factors for adenocarcinoma of the small intestine. Int J Cancer 1999; 82: 171-4.

5. Sigel JE, Petras RE, Lashner BA, et al. Intestinal adenocarcinoma in Crohn's disease: a report of 30 cases with a focus on coexisting dysplasia. Am J Surg Pathol 1999; 23: 651-5.

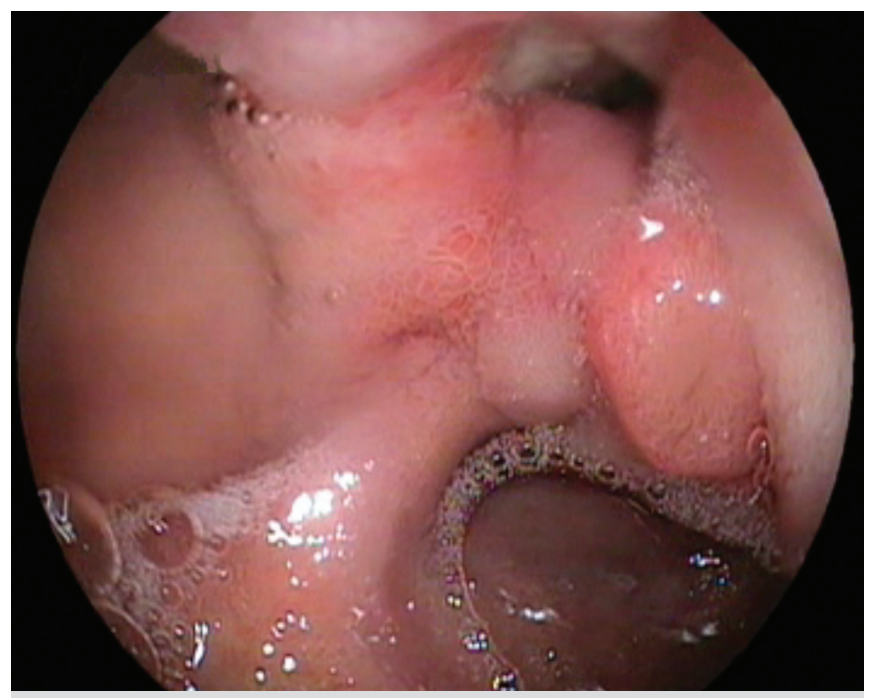

Şekil 2. Bulbusda ülsere kitle

Ince barsak adenokarsinomalarında uzun dönem sağkalım genel olarak kötüdür. Illk tanı anında anemi bulunması, sağkalımı dramatik olarak düzeltir. Bunun sebebi bu hastaların anemi nedeni ile tetkik edilirken genelde erken evrede yakalanan tümörlere sahip olmalarıdır (8).

Genellikle benign bir hastalık olduğu düşünülen bulbus ülserlerinde, özellikle ısrar eden şikayetlerin varlığında malignite olasılığına karşı dikkatli olmamız gerektiğini bu vaka dolayısı ile bir kere daha vurgulamak istedik.

6. Dabaja BS, Suki D, Pro B, et al. Adenocarcinoma of the small bowel: presentation, prognostic factors, and outcome of 217 patients. Cancer 2004; 101: 518-26.

7. Ito H, Perez A, Brooks DC, et al. Surgical treatment of small intestinal cancer: a 20-year single institution experience. J Gastrointest Surg 2003; 7:925-30

8. Veyrieres M, Baillet P, Hay JM, et al. Factors influencing long-term survival in 100 cases of small intestine primary adenocarcinoma. Am J Surg 1997; 173: 237-9. 